\title{
An immunological cryo-ultrastructural study of a sequential appearance of proteins in placental binucleate cells in early pregnancy in the cow*
}

\author{
G. Morgan, F. B. P. Wooding, J. F. Beckers $\dagger$ and H. G. Friesen $\ddagger$
}

AFRC Institute of Animal Physiology and Genetics Research, Babraham, Cambridge CB2 4AT, UK; $\uparrow$ Service d'Obstetrique, Faculté de Medicine Vetérinaire, Brussels, Belgium; and $\ddagger$ Department of Physiology, Faculty of Medicine, University of Manitoba, Winnipeg, Manitoba, Canada R3E 0W3

\begin{abstract}
Summary. Using the most sensitive immunocytochemical method available, on ultrathin frozen sections, the results in this paper demonstrate that bovine placental lactogen (bPL) is present in the earliest fetal binucleate cells found at 21 days post coitum in the trophectoderm. A second protein, the SBU-3 antigen, which is absent in the early stages of pregnancy appears abruptly in the binucleate cell granules at 30 days post coitum coincident with the start of villus development. Subsequently, the granules contain both bPL and the SBU-3 antigen. This sequential production of unlike proteins indicates that the binucleate cell has different functions depending on the stage of pregnancy and has important roles to play both at implantation and in villus development.
\end{abstract}

Keywords: immunology; ultrastructure; proteins; early pregnancy; cow

\section{Introduction}

Placental lactogenic hormones have been shown to be produced by fetal binucleate cells (BNC) in sheep (Martal et al., 1977; Wooding, 1981; Morgan et al., 1987) and cows (Verstegen et al., 1985; Wooding \& Beckers, 1987), throughout pregnancy. They are said to act as fetal growth hormones and change the mother's metabolism to benefit the fetus (Thordarson et al., 1987; Freemark et al., 1987). Morgan et al. (1987) using ultrathin frozen sections for electron microscopy (EM) localized ovine placental lactogen (oPL) to BNC granules in sheep at the earliest stage of placenta formation, coincident with implantation at 17 days post coitum (p.c.). However, the SBU-3 antigen (GogolinEwens et al., 1986) could not be demonstrated in BNC granules before the development of the fetal cotyledonary villi at a later stage ( 29 days p.c.). SBU-3 is a monoclonal antibody which recognizes an as yet uncharacterized glycoprotein found only in BNC granules and the Golgi bodies which produce them. Wooding \& Beckers (1987), using resin sections, found that bPL localization in cows was very weak before 28 days p.c. The present more sensitive cryosection study was undertaken to establish whether bPL was synthesized by the earliest BNC produced by the chorion (between 17 and 21 days p.c.) and whether the later appearance of SBU-3 in the BNC coincided with villus formation in the placenta of the cow, as in the sheep.

\section{Materials and Methods}

Friesian cows at 18,20,21,23,30,37, 135 and 260 days post coitum (p.c.) were killed by captive bolt pistol. The intact uteri were immediately removed and fixed by perfusion through both uterine arteries with $1 \%$ glutaraldehyde plus $3 \%$ (para)formaldehyde in $0.1 \mathrm{M}$-cacodylate buffer containing $5 \%$ sucrose. In addition $5-10 \mathrm{ml}$ fixative were injected into

*Reprint requests: Dr F. B. P. Wooding. 

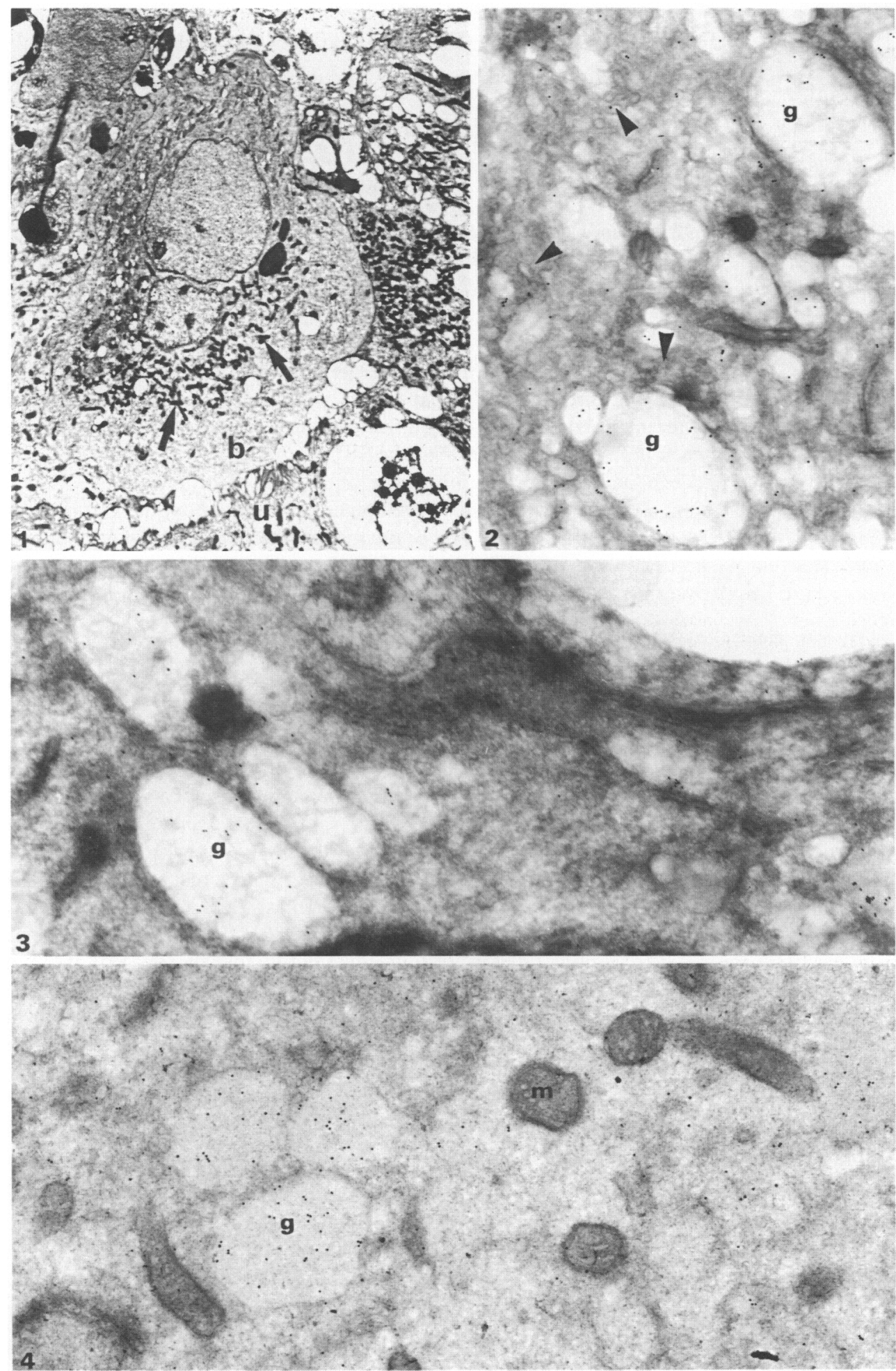
the uterine lumen $10 \mathrm{~min}$ after perfusion started. Total perfusion time was $20 \mathrm{~min}$ at room temperature. The uteri at Days 135 and 260 p.c. were also perfused via the fetal umbilical arteries. The uteri were then cut up into 5-cm lengths and left in fixative for a further $40 \mathrm{~min}$, after which time they were rinsed thoroughly and stored in $0.1 \mathrm{M}$-cacodylate buffer.

Samples of perfused cotyledons or caruncular areas where the blastocyst was adherent to the uterine epithelium were dissected out under a binocular microscope and orientated on the heads of metal pins (Reichert cryomicrotome supports) so that sections would be cut at right angles to the caruncular surface. The samples were then frozen by immersion in liquid nitrogen and sectioned at $-100^{\circ} \mathrm{C}$ with a Reichert OM FC4D cryo-ultramicrotome. The sections were transferred from the dry frozen glass knife, on the bottom of droplets of $2.3 \mathrm{M}$-sucrose in $0.1 \mathrm{M}$-phosphate buffer (pH 7.2), to touch down on and adhere to celloidin-covered 150-mesh nickel grids. The grids were floated section side down on a sequence of three drops of buffer for $10 \mathrm{~min}$ each to remove the sucrose. The sections, firmly adherent to the celloidin on their grids, were then incubated on a series of droplets of solutions on Nesco film in a Petri dish for immunogold localization of bPL or the SBU-3 antigen. Characterization of the bPL F, bPL B, and monoclonal SBU-3 antibodies are described by Murthy et al. (1982), Beckers et al. (1980, 1982) and Gogolin-Ewens et al. (1986), respectively. The first incubation was on heated $\left(60^{\circ} \mathrm{C}, 10 \mathrm{~min}\right)$ whole sheep serum diluted 1:10 with $0.1 \mathrm{M}$-Dulbecco phosphate-buffered saline $(\mathrm{pH} 7.2)$ containing $1 \%$ bovine serum albumin and $0.01 \%$ Thimerosal (a bacteriostatic) for $10 \mathrm{~min}$. (The above buffer was used for all antibody and gold dilutions.) The sections were then blotted free of excess heated whole sheep serum and incubated for $16 \mathrm{~h}$ at $4^{\circ} \mathrm{C}$ on anti-bPL at dilutions of 1:40 and 1:80 respectively, or for I h on undiluted hybridoma supernatant for SBU-3. After washing the grids with buffer from a wash bottle they were floated for $30 \mathrm{~min}$ on a drop of a $1 / 25$ dilution of Bioclin $10 \mathrm{~nm}$ colloidal gold particles coated with goat anti-rabbit (or goat anti-mouse for SBU-3) IgG (BioClin, Agar Scientific, Stansted, UK). They were then jet washed with buffer and floated on drops of $2 \%$ aqueous osmium tetroxide for $5 \mathrm{~min}$ to enhance the contrast and washed by floating on 4 drops of distilled water (jet washing with distilled water washed off the celloidin films). The sections were then stained on drops of $0 \cdot 25 \%$ aqueous methyl cellulose (Sigma, Poole, Dorset, UK: Cat No. MO262: viscosity of a $2 \%$ aqueous solution at $25^{\circ} \mathrm{C}$ approximately 400 centipoises). After $5 \mathrm{~min}$ the methyl cellulose has permeated sufficiently to act when dry as a reinforcing matrix for the sections, the excess is blotted off and the sections allowed to dry.

As specificity controls the initial antibody was replaced by heated whole sheep serum or by anti-bPL absorbed with pure bPL (the SBU-3 antigen is not yet available). Counts of the gold particles were made on the electron microscope. A wire loop attached to a pointer can be swung into the field of view of the JEOL $100 \mathrm{C}$ electron microscope and superimposed on the screen. This provides a constant size and the magnification of the image is selected to give between 5 and 25 gold particles within the area of the loop when positioned over the relevant cellular area. This magnification can be established quickly by an initial rapid qualitative scan of the section. Examples of the organelle or cell area under study (granule, cytoplasm, RER, Golgi body etc) are then selected at random, that is at a magnification at which the gold particles are not visible. The gold particles within the loop are then counted using the $\times 10$ eyepiece and recorded together with the magnification. From these two figures, given the area of the loop, the frequency of gold particles $/ \mu \mathrm{m}^{2}$ of each cellular inclusion can readily be calculated. This procedure is far quicker and as accurate (to within 5-7\%) as counting gold particles on standard magnification prints.

\section{Results}

\section{Localization of $b P L$}

At 18 and 20 days p.c. no mature BNC with granules were found but the occasional young BNC was identified, which showed no label in their rare granules. At 21 days p.c. a few more BNC were found but most of these were immature, containing few granules with a low level of gold labelling (Figs 1, 2, 3; Table 1). By 23-25 days the granule label has almost doubled (Figs 4, 5a, 5b; Table 1).

Fig. 1. Ultrathin frozen section of BNC (b) apposed to uterine epithelium (u). Note mitochondria (arrows) occasional granules (small arrowheads) and Golgi area between the white arrowheads. 21 days p.c.; $\times 2800$.

Fig. 2. Ultrathin frozen section of BNC Golgi body showing gold labelling using anti bPL B. Golgi cisternae and small vesicles (arrowheads), granules (g). 21 days p.c.; $\times 20000$.

Fig. 3. Ultrathin frozen section of BNC granules (g) showing gold labelling using anti bPL F. 21 days p.c.; $\times 20000$.

Fig. 4. Ultrathin frozen section of BNC granules (g) showing gold labelling using anti bPL F. Mitochondria $(\mathrm{m})$ are unlabelled. 23 days p.c.; $\times 23000$. 

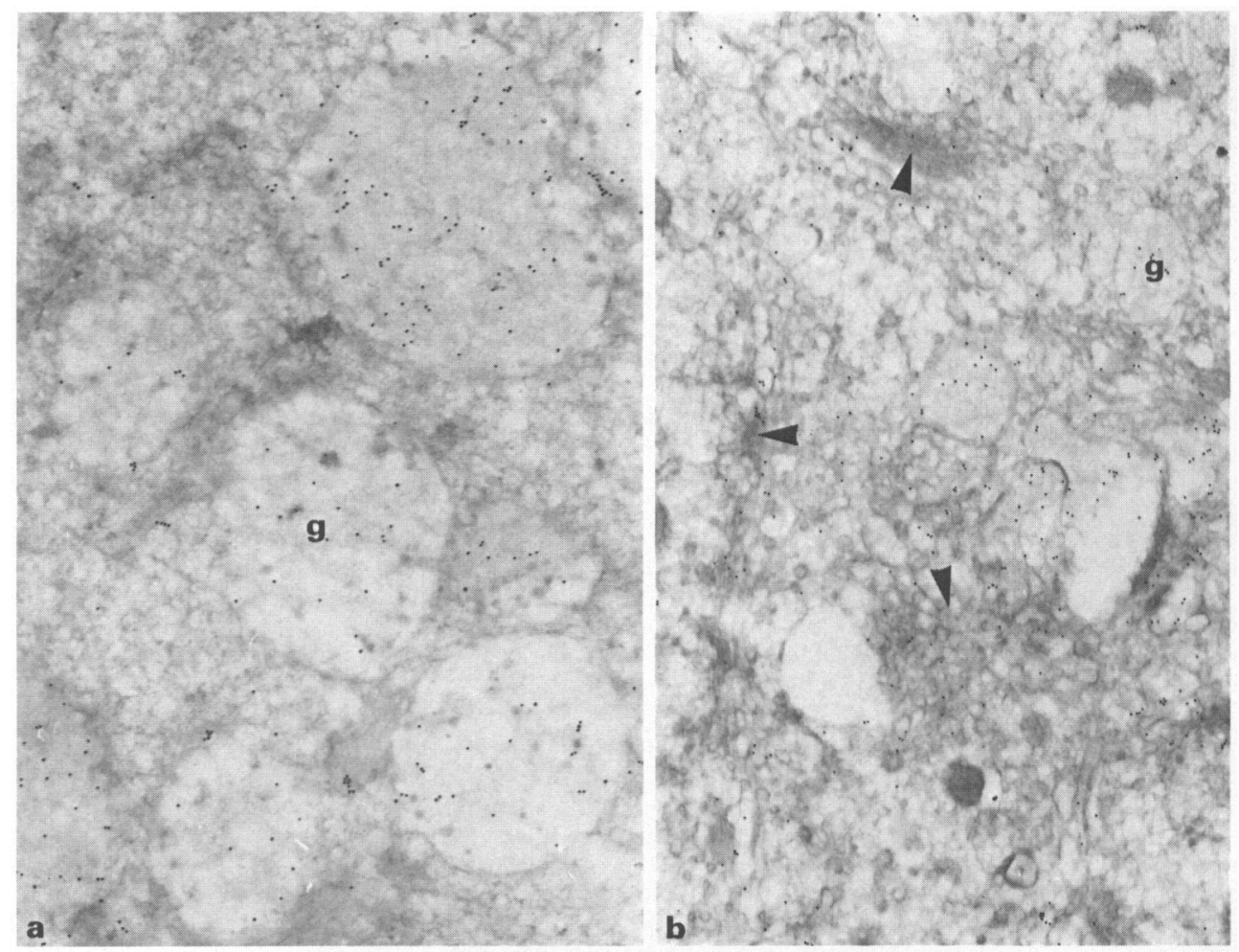

Fig. 5. Ultrathin frozen sections of BNC granules (g) (5a) and Golgi body cisternae (arrowheads) (5b) showing the strictly localized gold labelling using anti bPL F. (a) 25 days p.c.; $\times 23000$; (b) 25 days p.c.; $\times 25000$.

Similar results were obtained with both bPL B and F at 21 and 23 days p.c. but the bPL F was effective at lower dilution with a lower background level so was used for the remainder of the study. There was a further rise in gold labelling between 25 and 30 days p.c. with a slight increase to a fairly constant peak value between 135 and 260 days. BNC Golgi body label was approximately half that of their granules (Figs 2 and 5b; Table 1). Uterine 'giant' cell granule label was first detected at 23 days p.c. and was consistently less than BNC granule label (Table 1). Particle counts on sections treated with absorbed purified antibody (bPL) or heated whole sheep serum showed no area with gold particle frequency of $>0.7 \pm 0.2$ per $\mu \mathrm{m}^{2}$ ( $n=10$ for each).

\section{Localization of $S B U-3$}

No localization of SBU-3 was found before 30 days p.c. At 30 days, three groups of BNC in the trophectoderm could be distinguished by the degree of their granule labelling. No labelling was found in 5 BNCs, a low level of labelling was found in 11 and a high level of granule labelling was found in 55 of the BNCs counted (Figs 6a, 6b; Table 2). From 37 to 260 days, all BNC granules showed a similar high level of label which increased slightly at the later stages. The pattern of SBU3 labelling in BNC and uterine 'giant' cells was similar to that of bPL, i.e. the BNC Golgi body label was approximately half that seen on their granules, and uterine 'giant' cell granule label was consistently less than that found in BNC granules (Table 2). Uninucleate cells never showed any labelling significantly above background level over any organelle with either SBU-3 or bPL (Tables 1 and 2). Particle counts on sections treated with heated whole sheep serum showed no area with gold particle frequency of $>0.4 \pm 0.2$ per $\mu \mathrm{m}^{2}(n=10)$. 

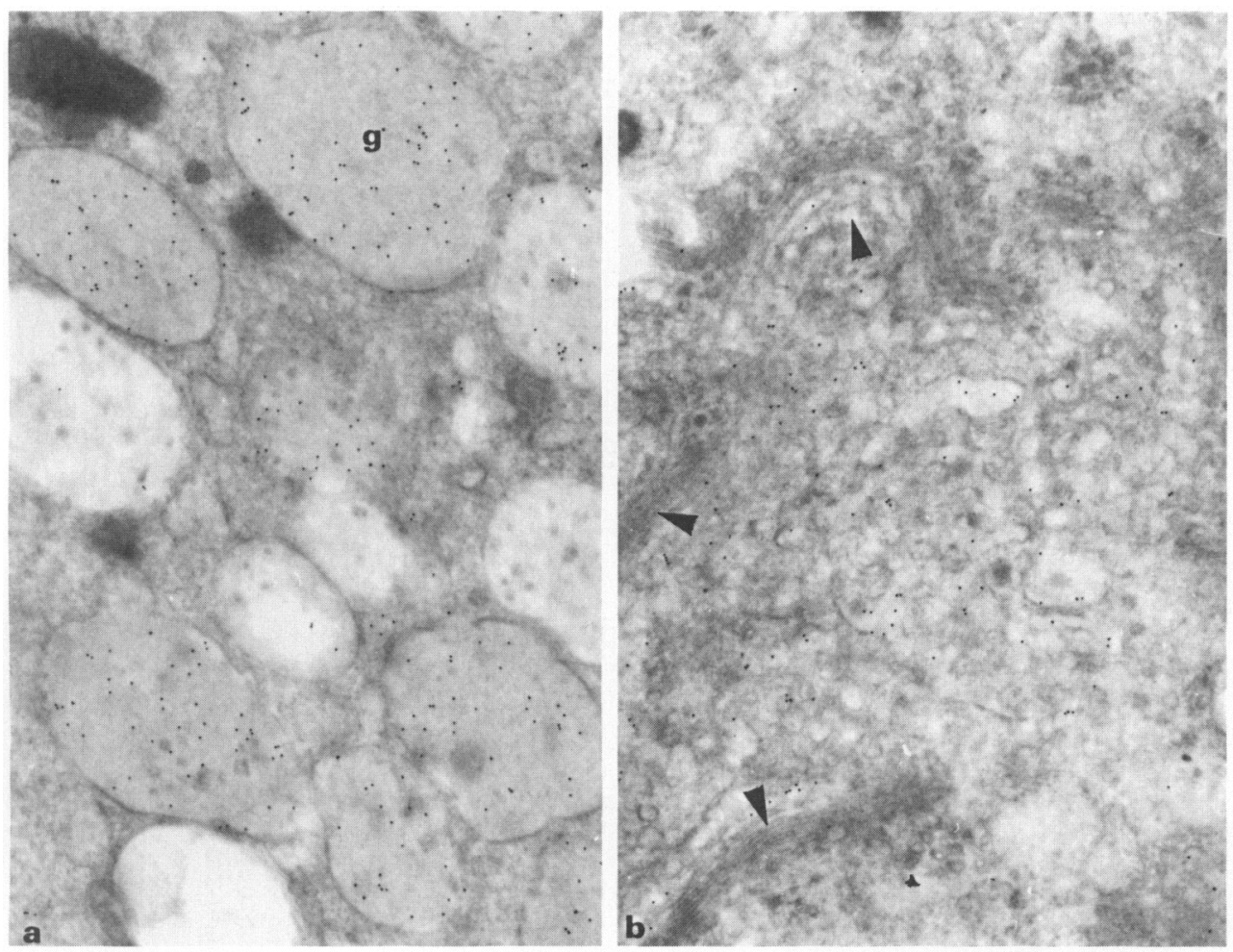

Fig. 6. Ultrathin frozen sections of BNC granules (g) (6a) and Golgi body cisternae (arrowheads), (6b) showing the localized gold labelling of the anti SBU-3 antigen. 30 days p.c.; $\times 23000$.

\section{Discussion}

The results clearly show that bovine trophectodermal binucleate cells (BNC) synthesize and store two defined proteins in sequence at specific times. The youngest conceptuses with mature granulated BNC were found at 21 days p.c. and immunolocalization on ultrathin cryo-sections showed that granules and Golgi bodies both contained bovine placental lactogen (bPL). When the fetal BNC had migrated to form fetomaternal tri- and multi-nucleate cells by fusion with uterine epithelial cells then these minisyncytia frequently showed granules, but never Golgi bodies, containing $\mathrm{bPL}$. This confirms the hypothesis that bPL is synthesized only by mature fetal BNC. BNC have been reported in the trophectoderm as early as 17-18 days p.c. (Greenstein et al., 1958) with no significant population before 20 days p.c. (Wooding, 1983). If the bovine BNC needs about $48 \mathrm{~h}$ to differentiate, as shown for the very similar ovine BNC (Wooding et al., 1981), then few mature BNC would be expected in cows before 19-20 days p.c. The absence of bPL-containing BNC in the material at 20 days could be due to the necessarily small samples used for cryo-ultramicrotomy allied to the wide variation in development between these early caruncular implantation sites and the inherent plus or minus 1 days inaccuracy of mating dates. BNCs containing bPL were first found at 21 days p.c. in this study, but they may be present 1 or 2 days earlier in small numbers. The amount of bPL per unit volume of granule increases far more in the first 30 days p.c. than in the subsequent 260 days. This is quite different from the high concentrations of oPL found in the earliest ewe BNC granules (17 days p.c.; Morgan et al., 1987) but the reason for this considerable species disparity is at present unknown. BNC ultrastructure shows no change during implantation in cows or sheep. 


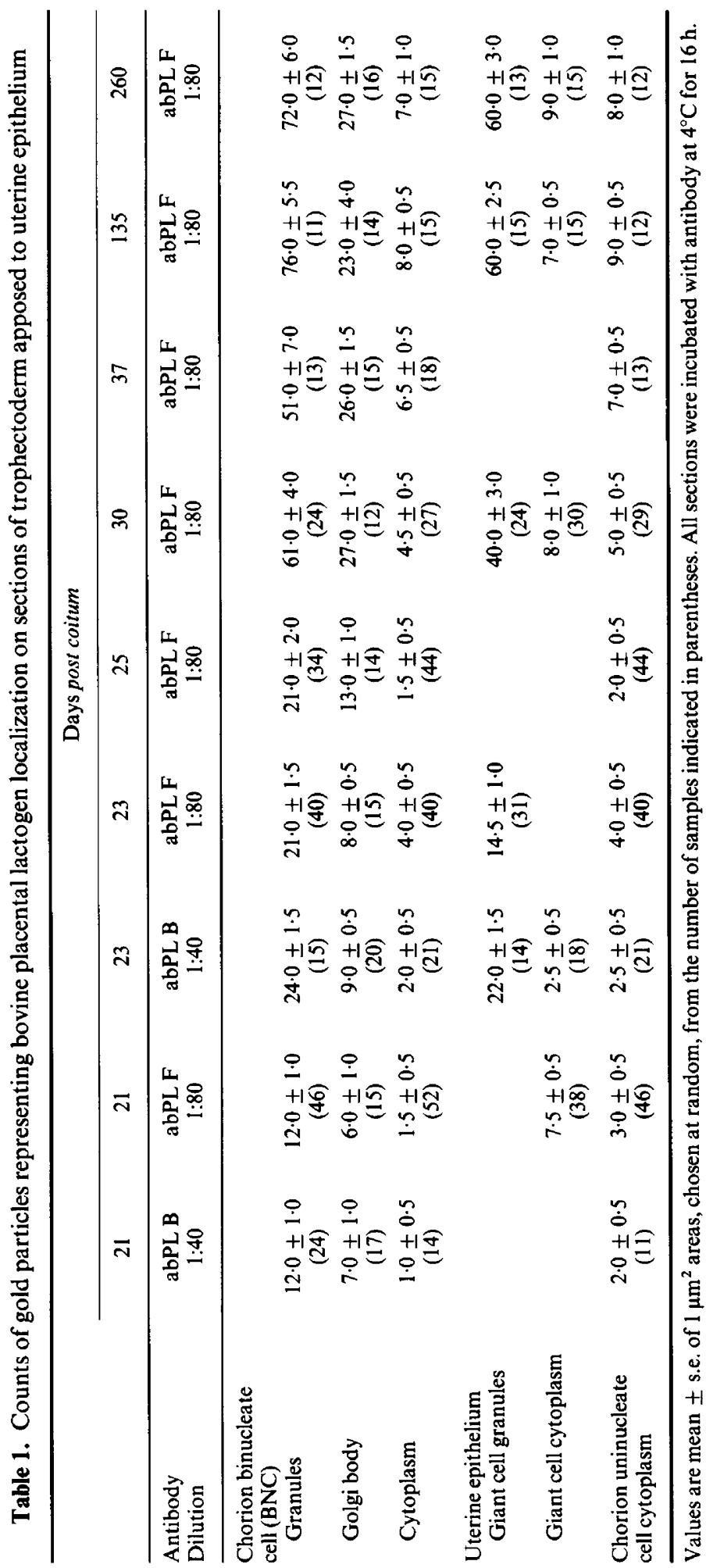


Table 2. Counts of gold particles representing SBU-3 antigen localization on sections of trophectoderm apposed to uterine epithelium

\begin{tabular}{|c|c|c|c|c|c|}
\hline & \multicolumn{5}{|c|}{ Days post coitum* } \\
\hline & 25 & 30 & 37 & 135 & 260 \\
\hline $\begin{array}{l}\text { Antibody, undiluted } \\
\text { hybridoma supernatant }\end{array}$ & aSBU-3 & aSBU-3 & aSBU-3 & aSBU-3 & aSBU-3 \\
\hline \multicolumn{6}{|l|}{$\begin{array}{l}\text { Chorion binucleate } \\
\text { cell (BNC) }\end{array}$} \\
\hline Granules & $\begin{array}{l}0 \cdot 5 \pm 0 \cdot 5 \\
(10)\end{array}$ & $\begin{array}{c}0.5 \pm 0.5 \\
(5) \\
3.0 \pm 0.5 \\
(11) \\
20.0 \pm 1.5 \\
(55)\end{array}$ & $\begin{array}{c}26 \cdot 0 \pm 1 \cdot 5 \\
(16)\end{array}$ & $\begin{array}{l}32 \cdot 0 \pm 2 \cdot 0 \\
(50)\end{array}$ & $\begin{array}{c}33 \cdot 0 \pm 5 \cdot 5 \\
\quad(31)\end{array}$ \\
\hline Golgi body & & $\begin{array}{l}5 \cdot 0 \pm 1 \cdot 0 \\
(16)\end{array}$ & $6 \cdot 0 \pm 1 \cdot 0$ & $\begin{array}{l}12 \cdot 0 \pm 1 \cdot 0 \\
\quad(11)\end{array}$ & $\begin{array}{c}12 \cdot 0 \pm 1 \cdot 0 \\
(13)\end{array}$ \\
\hline Cytoplasm & $\begin{array}{l}0 \cdot 5 \pm 0 \cdot 5 \\
(10)\end{array}$ & $\begin{array}{l}0 \cdot 5 \pm 0 \cdot 5 \\
\quad(23)\end{array}$ & $\begin{array}{l}0.5 \pm 0.5 \\
(10)\end{array}$ & $\begin{array}{l}0 \cdot 5 \pm 0 \cdot 5 \\
\quad(13)\end{array}$ & $\begin{array}{l}0 \cdot 5 \pm 0 \cdot 5 \\
\quad(15)\end{array}$ \\
\hline \multicolumn{6}{|l|}{ Uterine epithelium } \\
\hline Giant cell granules & & $\begin{array}{l}1 \cdot 0 \pm 0 \cdot 5 \\
(20)\end{array}$ & $\begin{array}{l}12 \cdot 0 \pm 1 \cdot 0 \\
(12)\end{array}$ & $\begin{array}{l}23 \cdot 0 \pm 1 \cdot 0 \\
(34)\end{array}$ & $\begin{array}{c}24 \cdot 0 \pm 2 \cdot 0 \\
(25)\end{array}$ \\
\hline Giant cell cytoplasm & & $\begin{array}{l}0.5 \pm 0.5 \\
\quad(10)\end{array}$ & $\begin{array}{l}0.5 \pm 0.5 \\
(10)\end{array}$ & $\begin{array}{l}0 \cdot 5 \pm 0 \cdot 5 \\
\quad(10)\end{array}$ & $\begin{array}{l}0 \cdot 5 \pm 0 \cdot 5 \\
\quad(14)\end{array}$ \\
\hline $\begin{array}{l}\text { Chorion uninucleate } \\
\text { cell cytoplasm }\end{array}$ & $\begin{array}{c}1 \cdot 0 \pm 0 \cdot 5 \\
(10)\end{array}$ & $\begin{array}{l}0.5 \pm 0.5 \\
(24)\end{array}$ & $\begin{array}{l}0.5 \pm 0 \cdot 5 \\
(10)\end{array}$ & $\begin{array}{c}0.5 \pm 0.5 \\
(13)\end{array}$ & $\begin{array}{l}0.5 \pm 0.5 \\
\quad(19)\end{array}$ \\
\hline
\end{tabular}

*At $18,20,21$ and 23 days, no areas in any cells counted higher than the background level $(0.5 \pm 0.5)$. Values are mean \pm s.e. of $1 \mu \mathrm{m}^{2}$ areas, chosen at random from the number of samples indicated in parenthesis. All sections were incubated with antibody at $4^{\circ} \mathrm{C}$ for $16 \mathrm{~h}$.

A second protein apparently unrelated to bPL but defined so far only by its monoclonal antibody (SBU-3: Gogolin-Ewens et al., 1986) and found in a wide variety of ruminant BNC granules from mid- to late pregnancy (Lee et al., 1985, 1986) was shown in this study to appear first in bovine $\mathrm{BNC}$ granules and Golgi bodies at 30 days p.c. Subsequently, it is a consistent granule constituent together with bPL. This increase in the number of proteins synthesized by the BNC is essentially similar to that found in the sheep with ovine placental lactogen and SBU-3 (Morgan et al., 1987). In the sheep the multinucleate syncytial plaques produced by the BNC migration into the uterine epithelium persist throughout pregnancy. However, the feto-maternal tri- and multi-nucleated cells produced at implantation in the bovine uterine epithelium are ephemeral and are rapidly displaced by regrowth of residual uterine epithelial cells. Bovine BNC migrate throughout pregnancy but only produce transient trinucleate cells (Wooding, 1982). The only consistent result of BNC migration in the cow is delivery of the $\mathrm{BNC}$ granule content to the maternal compartment from implantation to term (Wooding, 1987). The process starts several days too late to be associated with maintenance of the maternal corpus luteum but it does correlate with the need for immunomodulation by the mother to prevent rejection of the conceptus. Clark (1985) and Chaouat (1987) have provided evidence for rodents which suggests that trophectodermal secretions can recruit specific elements of the mother's immune system to ensure a local suppression of the immune response. In the cow the tri- and multinucleated plaques may form a more significant physical barrier against immune attack than the cellular uterine epithelium they replace. They may provide sufficient immune camouflage until a more permanent fetomaternal accommodation is reached possibly partly as a result of exocytosis of BNC granules into the maternal compartment. From their cytochemical reactivity there are undoubtedly constituents in the BNC granules at this stage 
other than the bPL demonstrated here, but as yet there is no evidence for defined immunological functions for any of the granule contents.

The BNC do not synthesize the protein to which SBU-3 is the monoclonal antibody until 30 days p.c. coincident with the start of villus formation. The development of the cotyledonary villi provides the increase in fetomaternal exchange area necessary to supply nutrients for growth of the fetus. BNC are concentrated at the tips of the forming villi, and it is possible that release of their granule content, which now includes the SBU-3 antigen, facilitates the tissue remodelling which accompanies villus development. The process does not proceed by erosion of and penetration into maternal tissue, but rather a mutual elaboration of fetal and maternal surfaces. Unlike bPL the SBU-3 antigen never reaches the maternal blood (Gogolin-Ewens et al., 1986) and so a local function is indicated. The SBU-3 antigen and other granule constituents could be involved in producing the considerable plastic deformation and massive cellular proliferation necessary for this process of cotyledonary villus development.

We thank Sue Billingsley for skilful technical assistance; Messrs J. H. Martin and R. Border for help in obtaining the pregnant cows; and Julie Brown for patient and highly efficient secretarial work.

\section{References}

Beckers, J.F., Fromont-Lienard, C.H., Van der Zwalmen, P., Wouters-Ballman, P. \& Ectors, F. (1980) Isolement d'une hormone placentaire bovine présentant un réactivité analogue à la prolactine et à l'hormone de croissance. Ann. Vet. Med. 124, 585-601.

Beckers, J.F., Decoster, R., Wouters-Ballmann, P., Fromont-Lienard, C.H., Van der Zwalmen, P. \& Ectors, F. (1982) Dosage radioimmunologique de l'hormone placentaire somatotrope et mammotrope bovine. Ann. Vet. Med. 126, 9-21.

Chaouat, G. (1987) Placental immunoregulatory factors. J. Reprod. Immunol. 10, 179-188.

Clark, D.A. (1985) Maternofetal relations. Immunol. Letters 9, 239-247.

Freemark, M., Cromer, M., Korner, G. \& Handwerger, S. (1987) A unique placental lactogen receptor: implications for fetal growth. Endocrinology 120, 1865 1872.

Gogolin-Ewens, K.J., Lee, C.S., Mercer, W.R., Moseby, A.M. \& Brandon, M.R. (1986) Characterisation of a trophoblast specific molecule. Placenta 7, 243-255.

Greenstein, J.S., Murray, R.W. \& Foley, R.C. (1958) Observations on the morphogenesis and histochemistry of the bovine preattachment placenta between 16 and 33 days of gestation. Anat. Rec. 132, 321-325.

Lee, C.S., Gogolin-Ewens, K., White, T.R. \& Brandon, M.R. (1985) Studies on the distribution of binucleate cells in the placenta of the sheep with a monoclonal antibody SBU-3. J. Anat. 140, 565-575.

Lee, C.S., Gogolin-Ewens, K. \& Brandon, M.R. (1986) Comparative studies on the distribution of binucleate cells in the placentae of the deer and cow using the monoclonal antibody, SBU-3. J. Anat. 147, 163-180.

Martal, J., Djiane, J. \& Dubois, M.P. (1977) Immunofluorescent localization of ovine placental lactogen. Cell Tiss. Res. 184, 427-433.

Morgan, G., Wooding, F.B.P. \& Brandon, M.R. (1987) Immunogold localization of placental lactogen and the SBU-3 antigen by cryoultramicrotomy at implantation in the sheep. J. Cell Sci. 88, 503-512.

Murthy, G.S., Schellenberg, C. \& Friesen, H.G. (1982) Purification and characterisation of bovine placental lactogen. Endocrinology 111, 2117-2124.

Thordarson, G., McDowell, G.H., Smith, S.V., Iley, S. \& Forsyth, I.A. (1987) Effects of continuous i.v. infusion of an ovine placental extract enriched in placental lactogen on plasma hormones, metabolites and metabolite biokinetics in non pregnant sheep. J. Endocr. 113, 277-283.

Verstegen, J., Fellman, D. \& Beckers, J.F. (1985) Immunodetection of the bovine chorionic somatomammotropin. Acta endocr., Copenh. 109, 403-410.

Wooding, F.B.P. (1981) Localization of ovine placental lactogen in sheep placentomes by electron microscope immunocytochemistry. J. Reprod. Fert. 62, 15-19.

Wooding, F.B.P. (1982) Structure and function of placental binucleate (giant) cells. Bibliotheca Anatomica 22, 134-139.

Wooding, F.B.P. (1983) Frequency and localization of binucleate cells in the placentomes of ruminants. Placenta 4, 527-540.

Wooding, F.B.P. (1987) Ultrastructural evidence for placental lactogen transport and secretion in ruminants. J. Physiol., Lond. 386, 26P, abstr.

Wooding, F.B.P. \& Beckers, J.F. (1987) Trinucleate cells and the ultrastructural localization of bovine placental lactogen. Cell Tiss. Res. 247, 667-673.

Wooding, F.B.P., Flint, A.P.F., Heap, R.B. \& Hobbs, T. (1981) Autoradiographic evidence for migration and fusion of cells in the sheep placenta; resolution of a problem in placental classification. Cell Biol. Int. Rep. 5, 821-827. 